\title{
V. On the continued rotation of a closed voltaic circuit, by another closed circuit
}

\section{Rev. William Ritchie LL.D. F.R.S.}

To cite this article: Rev. William Ritchie LL.D. F.R.S. (1834) V. On the continued rotation of a closed voltaic circuit, by another closed circuit , Philosophical Magazine Series 3, 4:19, 13-14, DOI: $10.1080 / 14786443408648243$

To link to this article: http://dx.doi.org/10.1080/14786443408648243

册 Published online: 01 Jun 2009.

Submit your article to this journal $\widetilde{ }$

ЏII Article views: 2

Q View related articles $₫$ 
rotation; and if the battery be removed, the ends of the roires brought into metallic contact, and the same motions be produced by mechanical means, the conductor will have the same electric state induced on it, as it had wohen connected roith the battery."

V. On the continued Rotation of a closed Voltaic Circuit, by another closed Circuit. By the Rev. William Rutchie, LL.D., F.R.S., Professor of Natural and Experimental Philosophy in the Royal Institution of Great Britain, and in the University of London*.

M AMPE'RE has demonstrated that when a closed cir1. cuit (or a conductor of voltaic electricity returning into itself so as to form a complete circuit, ) is acted upon by another closed circuit, there is a determinate position in which stable equilibrium takes place. Hence the impossibility of producing continued rotation by the mutual action of two closed voltaic circuits. Hence also the impossibility of producing continued rotation by the mutual action of two permanent magnets $t$. But though continued rotation cannot be produced by the action of closed circuits, when the voltaic influence is exerted in a particular direction, I have succeeded in producing such rotation by changing the direction of the voltaic influence; a short account of which may not be unacceptable to the readers of the Philosophical Magazine.

The description of the method will be easiest understood by reference to the annexed figure.

Let A B represent the section of a circular piece of wood, having a groove measuring about an inch in its inner diameter, and half an inch broad, for the purpose of holding mercury. The groove is divided into two compartments by small slips of wood fixed diametrically opposite to one another. These compartments may be connected by means of wires with the plates of an elementary battery.

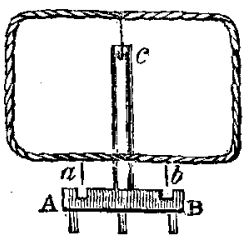
A glass rod, having a small cup, $c$, at the top, is cemented into the centre of the sole of the apparatus. A fine copper wire, covered with silk, is formed into a rectangular coil or closed circuit, as in the figure, the ends of which, $a b$, dip into the mercury contained in the compartments. The lower horizontal branch of the rectangle has the wires separated so

* Communicated by the Author.

+ This property was not known a few years ago, and hence an ingenious Scotch shoemaker contrived to gull the most eminent philosophers in Scotland, by a pretended perpetual motion, alleged to be produced by the mutual action of magnets. 


\section{Mr. G. H. Fielding's Reply to Sir David Brewster.}

as to form an opening for the glass rod to pass through it, in order that the rectangle may hang perpendicularly. A similar rectangular closed conductor is supposed to be connected with the poles of another battery.

If the last conductor be placed above that represented in the figure, but not parallel to it, as in the case of stable equilibrium, the moveable conductor will turn round till that position be gained. But the moveable conductor being put in motion will pass this position at the moment the ends of the wires, $a b$, pass above the two divisions in the groove, so that the direction of the voltaic influence is changed, and the moveable conductor forced round another semicircle, when the direction of the influence is again changed; and so on, producing continued rotation. By using a magnet instead of the closed conductor, a more powerful and rapid rotation may be produced. By placing the divisions in the magnetic meridian, the closed conductor may be made to revolve by the action of the earth.

This experiment, if I mistake not, will afford an interesting illustration of the mutual action of voltaic conductors, and of the striking analogy between a permanent magnet and a closed circuit conducting voltaic electricity.

VI. On the Membrana versicolor of the Eyes of Animals, in reply to Sir D. Brewster. By G. H. Fielding, Esq., M.R.C.S., Curator of Comparative Anatomy to the Hull Literary and Philosophical Society.

To the Editors of the Philosophical Magazine and Journal. Gentlemen,

I N your Number for October, I observe a communication from Sir David Brewster, which requires a few remarks from me by way of reply. It is entitled, " Notice respecting certain Changes of Colour in the Choroid Coat of the Eye." The principal object of the paper seems to be to claim for Dr. Drummond of Belfast the merit of being the first to notice the curious fact (which I mentioned in the Number of your Magazine for August last, as a discovery of my own,) of the disappearance by drying, and reproduction by wetting with water, of the brilliant colours of the choroid membrane of certain animals.

I was certainly not aware of the fact, as I had not seen the article "OpTIcs," of the Edinburgh Encyclopædia, nor ever heard of the experiment alluded to. The claim, however, is indisputable, and I with pleasure cede the palm of priority to Dr. Drummond. 